\title{
Effect of Ultrasonic Treatment on the Microstructure and Mechanical Properties of Hypereutectic Al-Si Alloy (A392)
}

\author{
تأثير الاهتزازات الفوق صوتيه علي البنيه المجهريه والخواص الميكانيكية \\ لسبيكة (A392) ألومنيوم-سيليكون الفين الفيهن \\ T.T. El-Midany ${ }^{1}$, M. Waly ${ }^{2}$, M.E. Moussa ${ }^{2}$, Y.M.A.Essa ${ }^{3, *}$ \\ ${ }^{1}$ Prof.of.Prod.Eng, Mansoura University, Egypt \\ ${ }^{2}$ Department of Manufacturing Technology, Laboratory of Foundry, Central \\ Metallurgical Research and Development Institute (CMRDI), P.O. 87, Helwan, \\ Egypt \\ ${ }^{3}$ Postgraduate student, Mansoura University, Egypt, \\ E-mail: yassergalya@gmail.com
}

يهدف هذا البحث الى در اسة تاثير المعالجة بالموجات الفوق الصوتيه عند درجات حرارة صب مختلفة (610، 640،

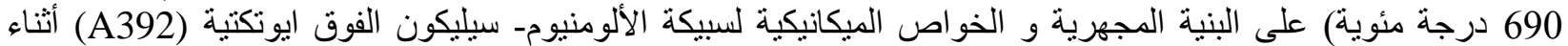

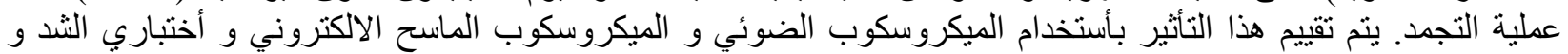

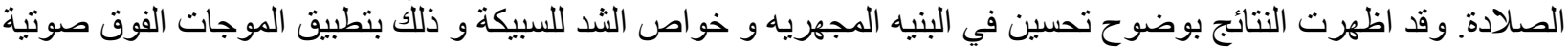

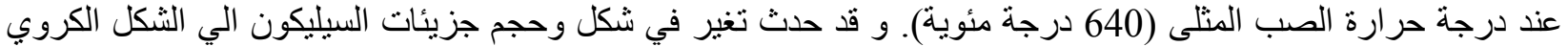

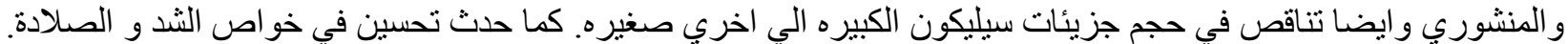
و ايضا تم در اسة سطح الكسر للسبيكة قبل و بعد المعالجة بالموجات الفيكات الفوق صوتية

\section{Abstract}

Hypereutectic Al-Si alloy (A392) was treated with ultrasonic vibration (UV) induced to the melt through a cylindrical resin-bonded sand mold. This work aims at studying the influence of UV at the different pouring temperatures of A392 alloy during solidification process on the microstructures and mechanical properties. The microstructures of as-cast samples were examined by using optical microscopy (OM) and scanning electron microscopy (SEM). The mechanical properties were investigated by tensile and hardness tests. The results showed clearly that with applied UV at optimum pouring temperature $\left(640{ }^{\circ} \mathrm{C}\right)$, nearly fine uniform and polyhedral shape of the primary Si were obtained. Improvement of tensile properties and hardness of the investigated alloy modified with UV is related to the modification and refinement of primary Si particles. The fracture surfaces of prepared alloy without and with UV were also investigated.

\section{Keywords:}

Aluminum-Silicon Alloy (A392); Ultrasonic Vibration; Microstructure; Mechanical Properties.

\section{Introduction}

Hypereutectic Aluminum-silicon based alloys have attracted attention because of their low thermal expansion, excellent wear resistance and high hardness. Silicon is the most important alloying in aluminum-silicon alloys, whereas the mechanical properties and fluidity increase, while the thermal expansion coefficient and density decrease. On the other hand, the wear resistance increases [1, 2]. Hypereutectic Al-Si alloys have been used in many products of industrial fields like the aerospace military industries and vehicle industries such as 
automotive cylinder block and high quality engine parts [3].

The mechanical properties of hypereutectic $\mathrm{Al}-\mathrm{Si}$ alloys depend mainly on the size and distribution of morphology silicon phases. For example, the tensile strength increases with the reduction of the size of Si particles. During solidification, the primary silicon particles are ready to grow coarsely, polygon or blocky crystal morphology which causes mechanical properties, and machinability to destroy [4].

The application of Ultrasonic melt treatment (UST) to the solidifying melts, causes microstructural changes, including refined grain size aluminum-silicon alloys, increased homogeneity and reduced segregation. The basic principle depends on introducing of acoustic waves with a frequency more than $17 \mathrm{kHz}$ into liquid metal [5, 6]. Puga et al [7], revealed that the high intensity vibration did not only promote the formation of the small $\alpha$-Al globular grains, but also modify the eutectic silicon, as well as decreasing the volume of porosity. High frequency and high amplitude oscillations result in cavitation of the melt and also promote intense mixing through agitation. Zhang et al [8], obtained that refinement of grains and primary Si particles when is ultrasonic applied vibration in a proper temperature range, while ultrasonic treatment during the whole solidification processing leads to coarsening effect on eutectic Si phase or primary Si particles. However, the ultrasonic treatment, as a new method for improving the solidification structure and the mechanical property of alloys, has recently been obtaining more attention.

The introduction of high-intensity ultrasonic vibrations into the molten alloys has been studied extensively as a refine microstructure. But few works have been carried out on the effects of ultrasonic vibration with different pouring temperature on microstructure and corresponding mechanical properties of hypereutectic $\mathrm{Al}-\mathrm{Si}$ alloys. Therefore, the objective of this work is to study the effect of ultrasonic treatment at different pouring temperatures on the microstructure and tensile properties of hypereutectic Al-Si alloy (A392).

\section{Experimental work}

\subsection{Materials}

Commercial hypereutectic Al-Si alloy (A392) with composition of (Al-18.66 wt. \% $\mathrm{Si}$ ) is provided by the supplier "Alu Company of Egypt". The chemical analysis of investigated alloy by using optical emission analytical is presented in Table1.

\begin{tabular}{l}
\hline \multicolumn{7}{c}{ Table1. Chemical composition of A392 } \\
alloy (wt. \%). \\
\hline \begin{tabular}{c|c|c|c|c|c|}
\hline $\mathrm{Si}$ & $\mathrm{Fe}$ & $\mathrm{Cu}$ & $\mathrm{Mn}$ & $\mathrm{Mg}$ & $\mathrm{Zn}$ \\
\hline 18.6 & 0.24 & 0.028 & 0.019 & 0.35 & 0.023 \\
\hline $\mathrm{Ni}$ & $\mathrm{Sn}$ & $\mathrm{Ti}$ & Other & $\mathrm{Al}$ \\
\hline 0.0016 & 0.0012 & 0.007 & 0.014 & \multicolumn{2}{|c|}{$\mathrm{Rem}$} \\
\hline
\end{tabular}
\end{tabular}

\subsection{Experimental procedure}

UST which was generated by using ultrasonic generator (model TS6MD1, Russia) and magnetostrict transducer (model PMS-15-22, Russia) with the maximum output power of $2.8 \mathrm{KW}$ and the fixed frequency of $20.8 \mathrm{kHz}$ was applied right before the melt was poured into cylindrical resin-bonded sand mold from the lower part of mold via the sonotrode which is made of titanium alloy Ti-6Al-4V as shown in Fig 1.

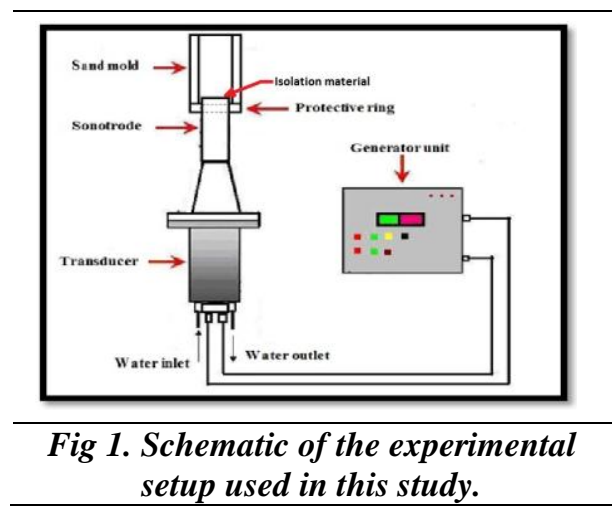


Charges of about 1000 grams of A392 alloy were melted in an electrically heat resistance furnace using a graphite crucible. For each charge, the investigated alloy was heated up to $750^{\circ} \mathrm{C}$ then allowed to cool until reaching the desired temperature, where thermocouple is used in measuring the temperature. After that, the molten A392 alloy was poured in a cylindrical resinbonded sand mold with dimensions of inner diameter $(\varnothing 42 \mathrm{~mm})$, outer diameter $(\varnothing 100$ $\mathrm{mm})$ and height $(200 \mathrm{~mm})$ which mounted on the ultrasonic sonotrode of diameter $(\varnothing$ $40 \mathrm{~mm}$ ) as shown in Fig 1. The reason for using a cylindrical resin-bonded sand mold is to reduce the cooling rate effect on the resulted microstructures of the prepared samples. Therefore, the difference in the morphology and size of eutectic $\mathrm{Si}$ in the microstructures of investigated samples were obtained mainly as a result of the difference in the application of UST conditions.

The effect of UST on solidification of A392 alloy was studied at different pouring temperatures $\left(610,640,690{ }^{\circ} \mathrm{C}\right)$ for the same application time of $600 \mathrm{~s}$. At the end of planed UST application time, the ultrasonic source was switched off and the melt was left to room temperature. Pouring temperatures were controlled within accuracy of $\pm 2{ }^{\circ} \mathrm{C}$. The ultrasonic waves emitted from the transducer and passed through the acoustic sonotrode were propagated directly into the melt during solidification. The poured melt became a part of acoustic sonotrode, so the action of ultrasonic energy on the melt was raised remarkably.

For comparison, a samples without the application of UST was prepared at same pouring temperatures of investigated alloy.

All metallographic specimens were cut from the bottom of castings at the same position of $10 \mathrm{~mm}$ above the sonotrode contact level of cylindrical samples as illustrated in Fig 1. After metallographic preparation, all samples were examined in an optical microscope (OM) and a scanning electron microscope (SEM) (model JSM $6510 \mathrm{LV}$ ). In the present study, the average length of primary $\mathrm{Si}$ was measured as the size of Si. Five optical microscope graphs were taken for each sample from the observed area at a magnification of $200 x$. The average size of the primary $\mathrm{Si}$ was measured by image analyzer software. All Si existed in one picture taken from the observed area were measured.

Tensile tests were performed using LFM-L-20KN Computer controlled and digital display electromechanical universal testing machine (model LFM-L-20KN (bench top), Switzerland) with a strain rate of $0.5 \mathrm{~mm} / \mathrm{min}$. The dimensions of a cylindrical tensile specimen are shown in Fig 2 according to ASTM E8M [9]. All tensile specimens were cut from the same position. SEM was used to characterize their fracture surfaces. Prior to SEM of their fracture surfaces, the samples were cleaned with ultrasonic and washed in acetone.

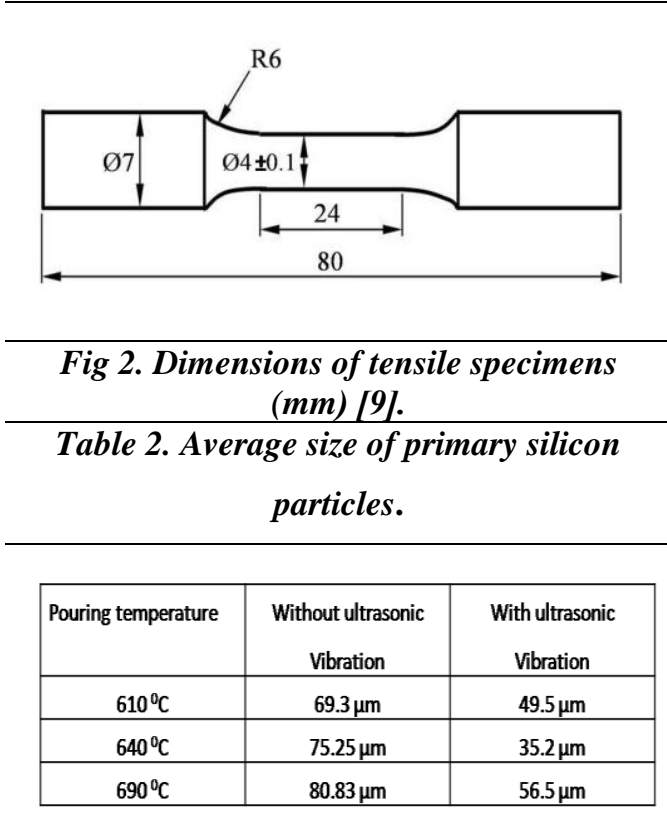

The Brinell hardness of the investigated samples is tested by using M295 Leeb Hardness Tester according to ASTM E8M [9]. All hardness specimens 
were cut at the same position of $10 \mathrm{~mm}$ from the bottom of castings and prepared similar to that of the metallographic specimens. The mean of five successful measurements was taken to establish the hardness values.

\section{Result and discussion}

\subsection{Microstructure}

As-cast microstructures of A392 alloy processed without $(\mathrm{a}, \mathrm{b}, \mathrm{c})$ and with $(\mathrm{d}, \mathrm{e}, \mathrm{f})$ UST at different pouring temperatures of 610, 640 and $690{ }^{\circ} \mathrm{C}$ are shown in Fig 3. The microstructures of hypereutectic A362 alloy reveal the presence of primary $\mathrm{Si}$ and eutectic $(\alpha \mathrm{Al}+\mathrm{Si})$ as shown in Fig 3 . Without UST, the primary Si shows a form of large faceted crystals and polygonal crystals, coarse plate-like phase with edges and corners and eutectic silicon is found as coarse plates as shown in Fig $3(a, b, c)$ [10].

The average size of the primary silicon is shown in Table 2. The average size of the primary silicon at pouring temperature of $610{ }^{\circ} \mathrm{C}$ is about $69.3 \mu \mathrm{m}$. At $640{ }^{\circ} \mathrm{C}$ and 690 ${ }^{0} \mathrm{C}$, the increase in the average size of the primary silicon reached about $75.25 \mu \mathrm{m}$ and $80.83 \mu \mathrm{m}$, respectively. Increase in the average size of silicon particles is followed by an increase of pouring temperature because the reduction of cooling rate and the number of nucleation sites.

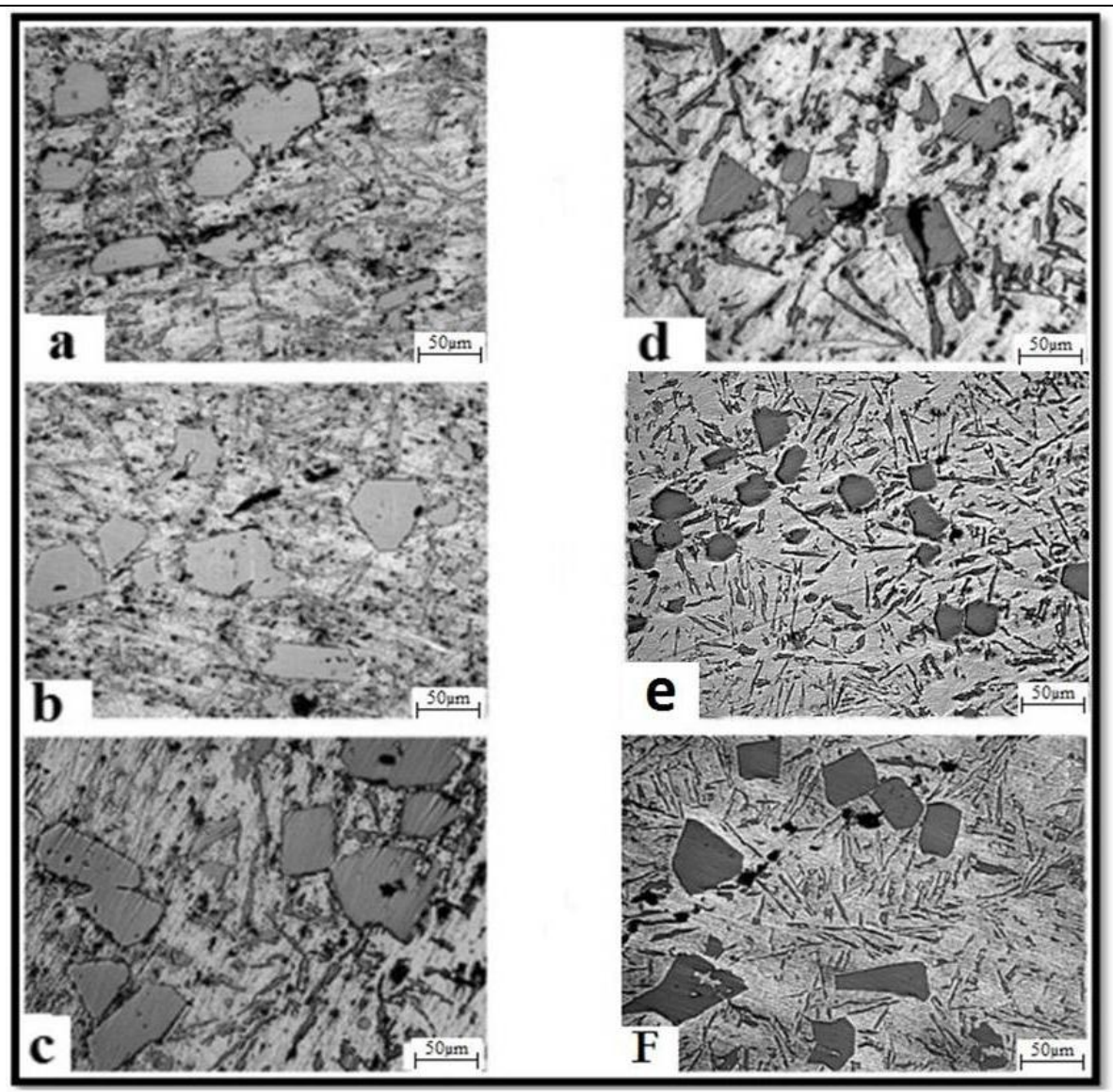

Fig.3.Comparison of the obtained microstructure without $(\mathrm{a}, \mathrm{b}, \mathrm{c})$ and with ultrasonic treatment $(\mathrm{d}, \mathrm{e}, \mathrm{f})$ at different pouring temperatures $\left(610^{\circ} \mathrm{C}, 640^{\circ} \mathrm{C}\right.$ and $\left.690^{\circ} \mathrm{C}\right)$ respectivel! 
With the application of UST for $600 \mathrm{~s}$ at pouring temperature of $610{ }^{\circ} \mathrm{C}$, most of primary Si particles are large faceted crystals and polygon crystals, with edges and corners, but their average size are reduced to about $49.5 \mu \mathrm{m}$, as shown in Fig $3 \mathrm{~d}$. As the pouring temperature increases from 610 to $640{ }^{\circ} \mathrm{C}$, most of primary $\mathrm{Si}$ particles become fine polyhedral shape and their average size are reduced significantly to about $35.2 \mu \mathrm{m}$, as shown in Figure $3 \mathrm{e}$. When the pouring temperature is further increased to $690{ }^{\circ} \mathrm{C}$, the average size of primary $\mathrm{Si}$ increases slightly again to about $56.5 \mu \mathrm{m}$, as shown in Fig 3f. Therefore, under the application of UST at different pouring temperatures for $600 \mathrm{~s}$, the average size of primary $\mathrm{Si}$ decreases significantly with increasing pouring temperature, reaches a minimum at $640{ }^{\circ} \mathrm{C}$, and then increases slightly with further increasing pouring temperature as compared without the application of UST, as shown in Table 2.

Under the present experimental conditions, the effect of the cooling rate on the modification of primary $\mathrm{Si}$ in the investigated hypereutectic A392 alloy could be described as negligible effect. Therefore, the difference in the morphology and size of primary Si resulted almost exclusively from the difference in the application of UST conditions. Usually, the microstructure of materials depends on the nucleation process and growth conditions [11].

The refinement and modification of primary Si can be mainly attributed to UST during the solidification process. This can be explained as conjugation of two mechanisms: cavitation-enhanced heterogeneous nucleation and cavitationinduced dendrite fragmentation. During the first stage of solidification between pouring temperatures and the liquids temperature of the investigated alloy, UST can only be attributed to cavitation-enhanced heterogeneous nucleation. This because dendrite fragmentation will not be possible at those temperatures since solidification has not started yet. The cavitation-enhanced heterogeneous nucleation is further explained by three different mechanisms.

The first is based on the pressure pulse-melting point $\left(\mathrm{T}_{\mathrm{m}}\right)$ mechanism [1114], where the pressure pulse arising from the collapse of bubbles alters $\mathrm{T}_{\mathrm{m}}$ according to the Clausius-Clapeyron equation [11] as follows:

$\mathrm{dT}_{\mathrm{m}} / \mathrm{dP}=\mathrm{T}_{\mathrm{m}}\left(\mathrm{V}_{\mathrm{L}^{-}} \mathrm{V}_{\mathrm{S}}\right) / \Delta \mathrm{H}$

where $T_{m}$ is the freezing point in $\mathrm{K}, \mathrm{P}$ is the pressure in $\mathrm{MPa}, \mathrm{V}_{\mathrm{L}}$ and $\mathrm{V}_{\mathrm{S}}$ are the specific volume of the liquid and the solid phase in $\mathrm{cm}^{3} / \mathrm{g}$, respectively, and $\Delta \mathrm{H}$ is the latent heat of freezing in $J$. An increase in $T_{m}$ is equivalent to increasing the undercooling so that an enhanced nucleation event is expected.

The second is based on cavitationenhanced wetting [11, 12], which assumes that cavities and cracks on the substrate surfaces and insoluble non-metallic inclusions that either pre-exist in the melt or form on cooling during solidification, can be wetted by the melt under the pressure pulse from the collapse of the bubbles. Consequently, this enables these substrates to act as effective nucleation sites.

The third mechanism $[11,12]$ assumes that rapid adiabatic expansion of gas inside the bubbles created during cavitation undercools the liquid at the bubble-liquid interfaces resulting in nucleation on the bubble surfaces. Collapsing of these bubbles will distribute the nuclei into the surrounding liquid producing a significant number of nuclei in the liquid.

Below the investigated liquids temperature, corresponding to the formation of the first solid metal, the cavitationinduced dendrite fragmentation is more effective and dominant. This mechanism assumes that the shock waves generated from the collapse of bubbles lead to 
fragmentation of dendrites at their roots [1113], which are redistributed through acoustic streaming, thereby increasing the number of crystals. The coexistence of these two mechanisms seems to promote a high density of nuclei in the melt, thus leading to the development of a large number of fine primary $\mathrm{Si}$ crystals which exhibit an octahedral morphologies with a variety of polygonal outlines in the two-dimensional view, such as triangle, square, trapezoid and hexagon because of the random cutting angles polishing process of metallographic samples.

The effect of UST at the different pouring temperatures on modification of primary $\mathrm{Si}$ on the investigated hypereutectic A392 alloy can be explained by the survival of the ultrasonically induced embryos in the melt. Since these embryos are not thermodynamically stable (they are formed only at the interfaces of the cavitation bubble and the melt during the expansion stage of the cavitation bubbles), they will be dissolved after the cavitation bubbles are collapsed in the melt [11]. As a consequence of such instability, the number of active nuclei in the melt was quite low, as well as their thermal stability at the pouring temperature $\left(690{ }^{\circ} \mathrm{C}\right)$ of the investigated alloy, resulting in coarse size of primary $\mathrm{Si}$, as shown in Fig 3f. When the pouring temperature $\left(610^{\circ} \mathrm{C}\right)$ is closer to the liquidus temperature $\left(588{ }^{\circ} \mathrm{C}\right)$ of the investigated alloy [2], the melt will be more viscous, so the formation of cavitation bubbles is more difficult. Thus, the quantity of embryos will be decreased in the melt. Therefore, the large faceted crystals and polygon crystals, with edges and corners of primary $\mathrm{Si}$ will be obtained microstructure as shown in Fig 3d. At the optimum pouring temperature $\left(640{ }^{\circ} \mathrm{C}\right.$ in this work), the embryos life time was long enough to promote a high density of nuclei in the melt, thus leading to the development of the finer polyhedral shape of primary $\mathrm{Si}$, as shown in Fig $3 \mathrm{e}$.

\subsection{Mechanical properties}

\subsubsection{Tensile test and Fractography Investigation}

Figures 4 and 5 show the effect of UST on the tensile strength and elongation of the investigated hypereutectic A392 alloy at the different pouring temperatures for $600 \mathrm{~s}$.

It can be found that the tensile strength and elongation of the investigated alloy with UST are higher than that of the investigated alloy without UST at the different pouring temperatures, implying that UST of the investigated hypereutectic A392 alloy can improve the tensile strength and elongation of this alloy. The ultimate tensile strength and elongation of the investigated alloy significantly increase from $106.86 \mathrm{MPa}$ and $2.65 \%$ without UST to $140.95 \mathrm{MPa}$ and $3.05 \%$ with UST at the pouring temperature of $640{ }^{\circ} \mathrm{C}$, respectively then gradually decrease with further increasing the pouring temperature. Therefore, the optimal ultimate tensile strength and elongation of the Investigated alloy can be achieved with UST at the optimum pouring temperature of 640 ${ }^{\circ} \mathrm{C}$ in this work.

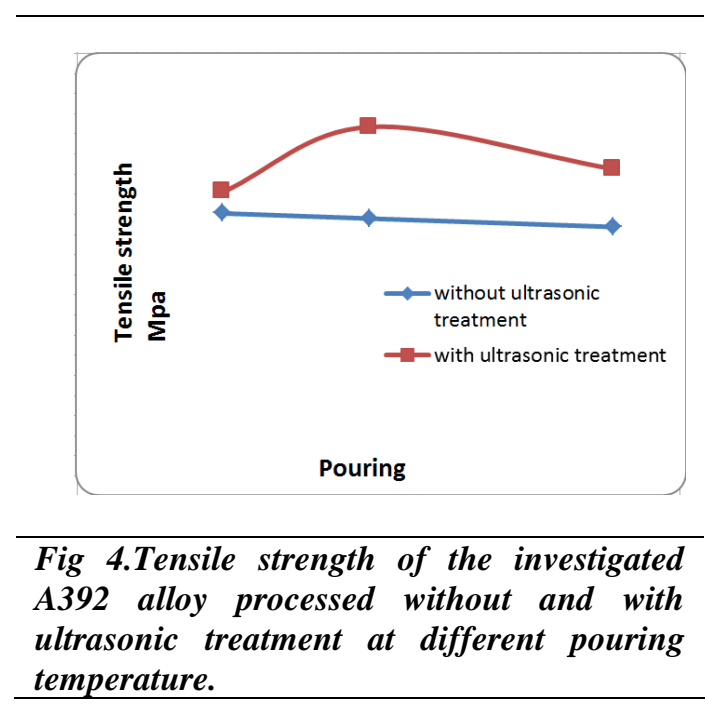

It is well known that the fine microstructure is usually beneficial to tensile properties of engineering alloys. According to Griffith's theory [14], the fracture stress of a material increase with decreasing of 
particle size, in inverse proportion to the square root of the particle size. Thus the refined structure has a higher tensile property, as it has been confirmed by other works in the Si containing magnesium alloys $[15,16]$. Therefore, it can be inferred that the improvement of the tensile properties for the investigated alloy modified by UST at the optimum pouring temperature of $640{ }^{\circ} \mathrm{C}$ for $600 \mathrm{~s}$ as compared with other pouring temperatures (Fig 4 and 5) is related to the superior modification and refinement of primary Si.

Figure 6 shows the SEM micrographs of the fracture surfaces of the investigated hypereutectic A392 alloy without and with UST at the pouring temperature of $640{ }^{\circ} \mathrm{C}$. The SEM micrographs of the fracture surface of the alloy without UST shows large facets, indicating brittle failure, as shown in Fig 6(a, c). The fracture planes of coarse primary $\mathrm{Si}$ particles exhibit clear cleavage with some secondary cracks created by a rapid fracture deriving from their intrinsic brittleness.

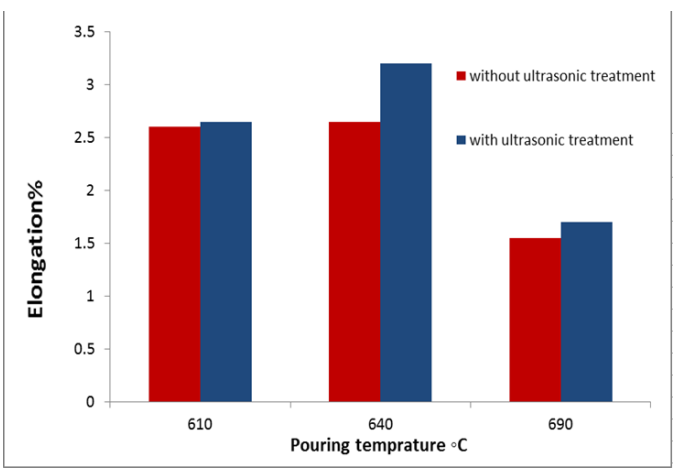

Fig 5. Elongation of of the investigated A392 alloy processed without and with ultrasonic treatment at different pouring temperature.
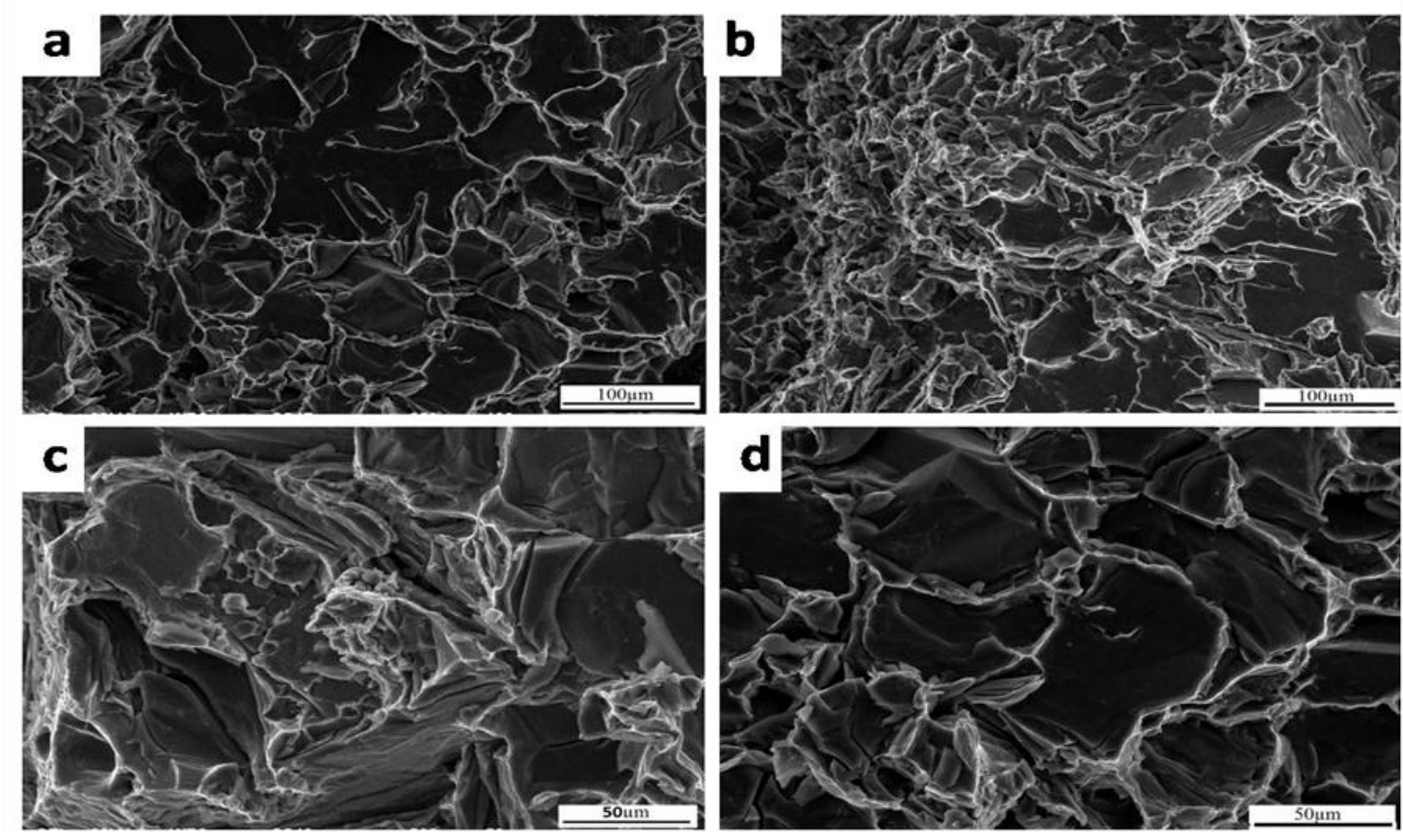

\footnotetext{
Fig 6. SEM micrographs of the fracture surfaces of the investigated A392 alloy. (a) without and (b) with UST at the pouring temperature of $640^{\circ} \mathrm{C}$; (c) large magnification of (a) and (d) large magnification of
} 
With UST, most of primary $\mathrm{Si}$ are modified and refined as well as the deformation zone on the fractograph of the alloy is enlarged considerably shown in Fig $6(\mathrm{~b}, \mathrm{~d})$, which increases its tensile strength and elongation. Furthermore, as shown in Fig $6(b, d)$, the appearances of dimples and the tearing deformation inside the crystal are clearly observed, the cleavage fracture characteristics are weakened. Therefore, the fracture mechanisms of modified alloy become the hybrid fracture mechanisms: the plastic fracture and cleavage fracture.

\subsubsection{Hardness}

The average Brinell hardness values of the investigated hypereutectic A392 alloy with UST at the different pouring temperatures for $600 \mathrm{~s}$ are illustrated in Table 3. It can be found that the average hardness value of the investigated alloy with UST is higher than that of the alloy without UST, implying that UST of the investigated hypereutectic A392 alloy can improve the hardness of this alloy. The average hardness value of the investigated alloy significantly increases from $45.66 \mathrm{HB}$ without UST to 61.25 HB with UST at the pouring temperature of $640{ }^{\circ} \mathrm{C}$, then gradually decreases with further increasing pouring temperature. Therefore, the optimal hardness value of the investigated alloy can be achieved with UST at the pouring temperature of $640{ }^{\circ} \mathrm{C}$ in this work. This is basically coincident with this superior effect on the modification and refinement of primary Si in the hypereutectic A392 alloy. From this result, it may be considered that the ultrasonic vibration can enhance the hardness level, which is similarly reported in a previous study by Abramov et al. [17]. They reported that the high hardness is obtained for the high purity aluminum with the UV treatment, which is about $14 \%$ higher than that for the related sample before the UV process.

Table 3. The average hardness values of A392 alloy without and with ultrasonic treatment.

\begin{tabular}{|c|c|c|}
\hline $\begin{array}{c}\text { Pouring } \\
\text { Temperature } \\
{ }^{\mathbf{C}}\end{array}$ & $\begin{array}{c}\text { Without } \\
\text { ultrasonic } \\
\text { treatment } \\
\text { (HB) }\end{array}$ & $\begin{array}{c}\text { With } \\
\text { ultrasonic } \\
\text { treatment } \\
\text { (HB) }\end{array}$ \\
\hline 610 & 49 & 51 \\
\hline 640 & 45.66 & 61.25 \\
\hline 690 & 40.75 & 51.66 \\
\hline
\end{tabular}

\section{Conclusion}

[1] UST has a significant effect on the modification and refinement of primary $\mathrm{Si}$ in the hypereutectic A392 alloy during the solidification process.

[2] The modification mechanism of the hypereutectic A392 alloy due to the application of UST is mainly attributed to the conjugation of two mechanisms: cavitation-enhanced heterogeneous nucleation and cavitation-induced dendrite fragmentation.

[3] For the ultrasonic application time of $600 \mathrm{~s}$, the coarse primary Si is obtained at both lower and higher pouring temperatures of 610 and $690{ }^{\circ} \mathrm{C}$, respectively. Therefore, fine polyhedral shape of primary Si can be obtained at optimum pouring temperature of 640 ${ }^{\circ} \mathrm{C}$.

[4] The improvement of the tensile strength, elongation and hardness of the hypereutectic A392 alloy modified by UST is related to the modification and refinement of primary $\mathrm{Si}$.

[5] Tensile fracture behavior of the hypereutectic A392 alloy treated with UST at the pouring temperature of 640 ${ }^{\circ} \mathrm{C}$ for $600 \mathrm{~s}$ changed from cleavage fracture mode to the hybrid fracture mechanisms: the plastic fracture and cleavage fracture. 


\section{Reference}

[1] W. Khalifa , S. il-hadad, and Y.Tsunkawa:" Microstructure and Wear Behavior of Solidification Sonoprocessed B390 Hypereutectic Al-Si Alloy", Metallurgical and materials transaction, Vol. 44A, December 2013 - 5817.

[2] N. U. nal, H. E. Camurlu, S. Kocak and G. Duztepe: "Effect of external ultrasonic treatment on hypereutectic cast aluminum-silicon alloy", International Journal of Cast Metals Research, Vol. 25, No. 42012,

[3] H.K. Fenga, S.R. Yua,, Y.L. Li and L.Y. Gong:" Effect of ultrasonic treatment on microstructures of hypereutectic Al-Si alloy", journal of materials processing technology, 2008.

[4] Y. Tsunekawa1, S. Suetsugu, M. Okumiya1, N. Nishikawa, and Yoshikazu Genma: "Improvement in mechanical properties of hypereutectic $\mathrm{Al}-\mathrm{Si}-\mathrm{Cu}$ alloys through sonosolidified slurry", Celebrating the 10th Anniversray, Vol.11 No.4 July 2014.

[5] L. Zhang, D. G. Eskin, L. Katgerman: "Influence of ultrasonic melt treatment on the formation of primary intermetallics and related grain refinement in aluminum alloys", Journal Material Science, Vol. 46,No . 5252-5259, 2011.

[6] Z. Sarajan, M. R. S. Tahmorsati: "Effect of Ultrasonic Treatment on Microstructure of Eutectic Al-Si Alloy",AIP.

Conf.Proc,No.1400,PP,172-175,2011.

[7] H. Puga , J.Barbosa , S.Costa , S.Ribeiro, A.M.P.Pinto and M.Prokic: "Influence of indirect ultrasonic vibration on the microstructure and mechanical behavior of $\mathrm{Al}-\mathrm{Si}-\mathrm{Cu}$ alloy", Materials Science \& Engineering Vol.560 PP. 589595,2013 .
[8] L. Zhang, D.G. Eskin, A. Miroux and L. Katgerman1:" Formation of microstructure in AL-SI alloys under ultrasonic melt treatment", The Minerals, Metals \& Materials Society,2012.

[9] Annual Book of ASTM Standards, 2006, "Metals-mechanical testing; elevated and low-temperature tests; metallography", Baltimore, MD, U.S.A., ASTM international, Vol. 03.01 .

[10] Chong LIN, Shu-sen WU, Gu ZHONG, Li WAN, Ping AN, "Effect of ultrasonic vibration on $\mathrm{Fe}$ containing intermetallic compounds of hypereutectic $\mathrm{Al}-\mathrm{Si}$ alloys with high Fe content", Transaction of Nonferrous Metals Society of China Vol. 23, 2013, 1245-1252.

[11] M.E. Moussa, M.A. Waly and A.M. El-Sheikh, "Effect of high-intensity ultrasonic treatment on modification of primary $\mathrm{Mg}_{2} \mathrm{Si}$ in the hypereutectic $\mathrm{Mg}-\mathrm{Si}$ alloys", Journal of Alloys and Compounds, Vol. 577, 2013 693-700.

[12] M.E. Moussa, M.A. Waly and A.M. El-Sheikh, "Combined effect of highintensity ultrasonic treatment and $\mathrm{Ca}$ addition on modification of primary $\mathrm{Mg}_{2} \mathrm{Si}$ and wear resistance in hypereutectic $\mathrm{Mg}-\mathrm{Si}$ alloys", Journal of Alloys and Compounds, Vol. 615, 2014, 576-581.

[13] H. Yan, Y. Rao and R. He, "Morphological evolution of semisolid $\mathrm{Mg}_{2} \mathrm{Si} / \mathrm{AM} 60$ magnesium matrix composite produced by ultrasonic vibration process", Journal of Materials Processing Technology, Vol. 214, 2014, 612-619.

[14] B. Patel, G.P. Chaudhari and Bhingole P.P., "Microstructural evolution in ultrasonicated AS41 magnesium alloy", Materials Letters, Vol. 66, 2012, 335-338. 
[15] M.Q. Cong, Z.Q. Li, J.S. Liu and S. Li, "Effect of Sr on microstructure, tensile properties and wear behavior of as-cast Mg-6Zn-4Si alloy", Materials and Design, Vol. 53, 2014, 430-434.

[16] C. Mengqi, L. Ziquan, L. Jinsong and L. Shaohua, "Effect of $\mathrm{Sr}$ on microstructure, tensile properties and wear behavior of as-cast $\mathrm{Mg}-6 \mathrm{Zn}-4 \mathrm{Si}$ alloy", Materials and Design, Vol. 53, 2014, 430-434.

[17] Abramov, V.; Abramov, O.; Bulgakov, V.; Sommer, F.:"Solidification of aluminum alloys under ultrasonic irradiation using water-cooled resonator". Material Letter, Vol. 37, 1998, 27-34. 